\title{
LIFE THREATENING BLEEDING FROM A GASTROINTESTINAL STROMAL TUMOUR: A CASE REPORT
}

\author{
J. Ray ${ }^{1}$, S.K. Sahu ${ }^{\circledR}$, S. Kumar ${ }^{1}$, V.K. Dhingra ${ }^{2}$, V. Asthana ${ }^{3}$, \\ S. Negi ${ }^{1}$, U. Sharma ${ }^{1}$ \\ 1) Department of General Surgery \\ 2) Department of Nuclear Medicine \\ 3) Department of Anaesthesiology \\ Himalayan Institute of Medical Sciences, \\ Himalayan Institute Hospital Trust (HIHT) University, Swami Ram Nagar, Dehradun, India

\begin{abstract}
LIFE THREATENING BLEEDING FROM A GASTROINTESTINAL STROMAL TUMOUR: A CASE REPORT (Abstract): Gastrointestinal stromal tumours (GIST) are rare tumours of the gastrointestinal tract. They can cause massive gastrointestinal haemorrhage as illustrated in our case. Our patient was admitted to the emergency in shock due to massive haematochezia. The patient was revived with multiple transfusions and crystalloids. 99m-Tc labeled Red Blood Cells (RBC) scan showed bleeding from right upper quadrant of abdomen. Laparotomy revealed a tumour in jejunum which was resected and proved to be GIST by immunohistochemistry. The patient improved dramatically after surgery and his haemoglobin level stabilized at $10 \mathrm{~g} / \mathrm{dL}$. Repeat RBC scan revealed that there was no bleeding. The postoperative recovery was uneventful. CONCLUSION: GISTs are rare but clinical important tumours. As in our case they can cause life threatening bleeding. Intensive care to stabilize the patient and modern diagnostic methods like RBC scan has proved invaluable. Segmental enterectomy has been the definitive treatment the tumour and the gastrointestinal haemorrhage.
\end{abstract}

\section{KEY WORDS: GIST; STROMAL TUMOUR; UPPER DIGESTIVE BLEEDING;} ENTERECTOMY;

SHORT TITLE: Life threatening bleeding from a GIST

HOW TO CITE: Ray J, Sahu SK, Kumar S, Dhingra VK, Asthana V, Negi S, Sharma U. Life threatening bleeding from a gastrointestinal stromal tumour: a case report. Jurnalul de chirurgie (Iaşi). 2013; 9(4): 335-338. DOI: 10.7438/1584-9341-9-4-5.

\section{INTRODUCTION}

Gastrointestinal stromal tumours (GIST) are rare tumours of the gastrointestinal tract. They originate from gastrointestinal pacemaker cells and are characterized by over-expression of the tyrosinekinase receptor cKIT. [1,2]

\section{CASE REPORT}

A 42 year male presented to the emergency department with complaints of massive bleeding per rectum after he was operated by a local quack for suspected haemorrhoids two days back. The patient was in shock and very pale. At admission his blood pressure was $60 / 40 \mathrm{mmHg}$, pulse $120 /$ min and was having acute respiratory distress.

Large volumes of crystalloids were infused in an attempt to revive him, but he was having severe respiratory distress and ongoing bleeding per rectum. He was intubated and shifted to the intensive care unit. Routine investigations revealed 
haemoglobin $2.6 \mathrm{~g} / \mathrm{dL}$ and platelet count $40,000 / \mathrm{mm}^{3}$. Multiple transfusions of packed RBC and platelets were used to stabilize him. Examination under anaesthesia was done in the operation theatre in suspicion of bleeding haemorrhoids, but the source was not found in the anorectum. It was inferred that the bleeding was from more proximal part.

After stabilising a RBC scan was performed on the patient. The source of bleeding was reported to be in the right lumbar region of the abdomen (Fig 1).

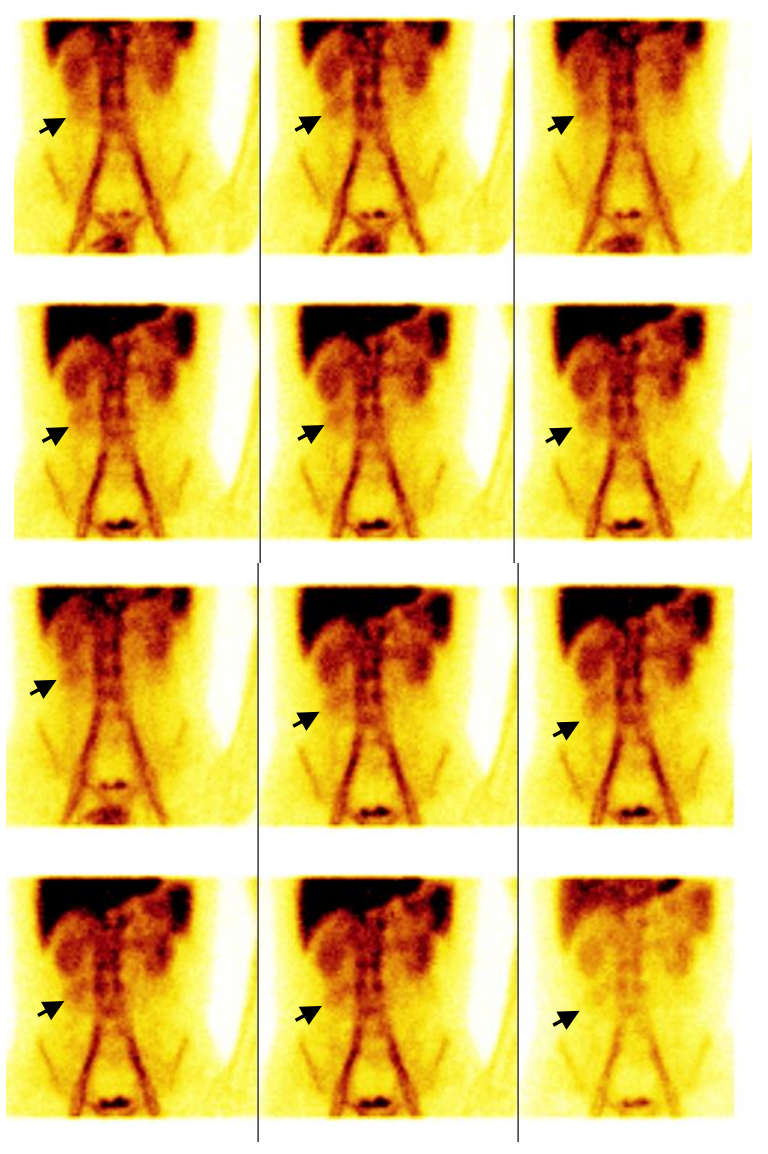

Fig. 1 Preoperative Tc-99m RBC labelled radionuclide scan: tracer accumulation seen in the right lumber region (arrow) suggestive of bleed

A provisional diagnosis of angiodysplasia of right colon was made. The patient was further transfused packed RBC and platelets and taken up for emergency exploratory laparotomy. On laparotomy a firm growth of about $4 \mathrm{~cm}$ diameter was found in the antimesenteric border of jejunum about one and a half feet distal to the duodenojejunal flexure (Fig. 2).

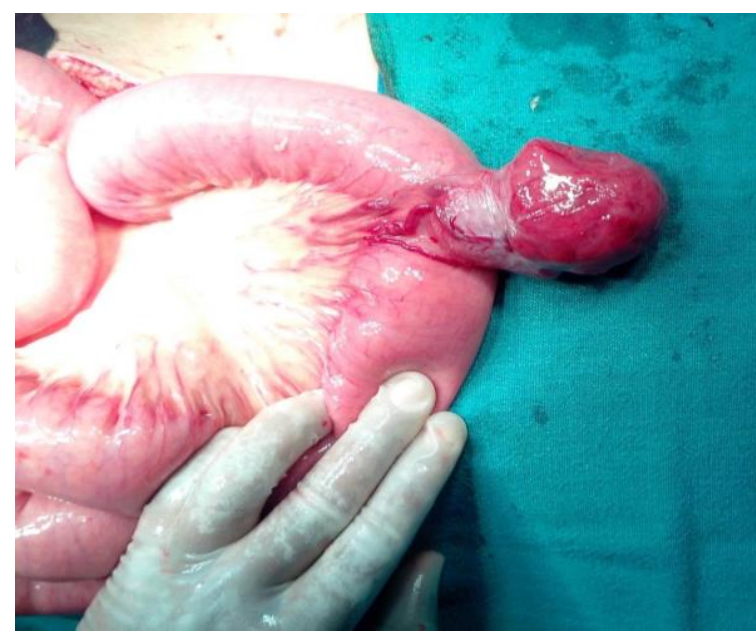

Fig. 2 Tumour of about $4 \mathrm{~cm}$ diameter was found in the antimesenteric border of jejunum

The vessels supplying the growth appeared dilated and thin walled. No regional lymph node was enlarged. No peritoneal deposits could be found. The growth was resected with the segment of jejunum containing it with adequate free margin of $5 \mathrm{~cm}$ and end-to-end anastomosis of jejunum was done (Fig. 3). The patient improved dramatically after surgery and his haemoglobin level stabilized at $10 \mathrm{~g} / \mathrm{dL}$. Repeat RBC scan revealed that there was no bleeding. (Fig. 4) The postoperative recovery was uneventful.

Histopathologic study revealed a spindle cell tumour arising from the smooth muscle layer of jejunum. Immunohistochemistry for KIT receptor tyrosine kinase (KIT, CD 117) was positive and the diagnosis of GIST was confirmed. The patient has thrived well and with no sequelae.

\section{DISCUSSION}

The mesenchymal tumours have been classified over the years into leiomyomas, schwannomas, leiomyoblastomas or leiomyosarcomas. But in recent years there has been more insight into the origin of these tumours. Mazur and Clark in 1984 reported that many supposed smooth muscle tumors lacked immunohistochemical or electron microscopic evidence of smooth muscle or neural characteristics, and they suggested that the term "gastric stromal tumor" would 
be more appropriate [1]. Kindblom proposed that these tumours arise from the interstitial cells of Cajal which are pacemaker cells of the gut [2]. They originate from gastrointestinal pacemaker cells and are characterized by over-expression of the tyrosine kinase receptor cKIT.

Though rare, gastrointestinal stromal tumours (GIST) are the most common mesenchymal tumours of the gut. GISTs are rare tumours but the most common mesenchymal tumours of the gastrointestinal tract. Studies from Finland show the annual incidence to be about 10-20 / million [3].

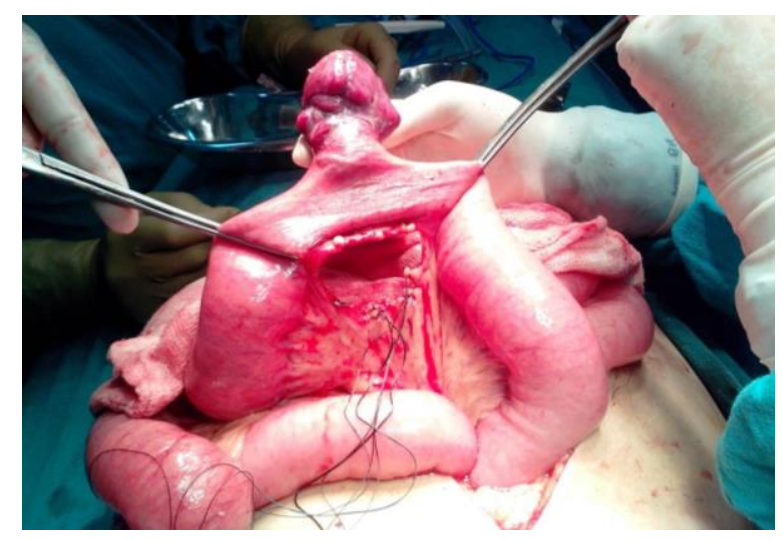

Fig. 3 Segmental small bowel resection.

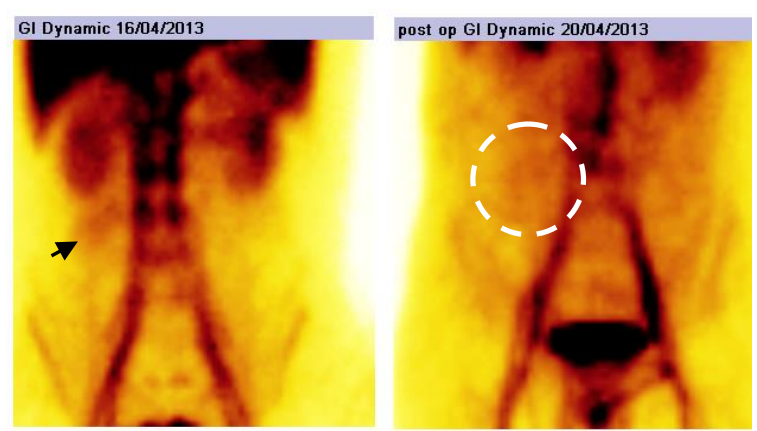

Fig. 4 Pre and postoperative Tc99m labelled RBC radionuclide scan: The focal area seen previously is not visualized on the postoperative scan (arrows)

Most GISTs arise in the stomach (about 60\%) and small intestine (30\%), and less commonly from the duodenum, the colon and rectum. GIST of oesophagus is extremely rare [4-6]. No significant difference in incidence between males and females has been noted. Median age of presentation is 69 [7].

The symptoms depend upon the size of the tumour. Small GISTs are usually asymptomatic and are incidental findings in laparotomies for other conditions. Larger tumours may present as bleed, abdominal masses, cause obstruction or rarely perforate. Bleeding is the most common presentation of GIST (about 50\%) [8]. Bleeding can be chronic causing unexplained anaemia or may be acute. Acute bleeding can be life threatening necessitating emergency management [9]. About $10 \%$ cases at presentation have metastatic disease. The most common site of secondaries is liver. Peritoneal metastases are uncommon and lymphatic spread is rare [5].

There are no recognized specific radiological examinations for GIST diagnosis. Endoscopy can reveal submucosal masses and ulcerated mucosa. But often the mucosa appears normal. Contrast enhanced $\mathrm{CT}$ is mainstay of diagnosis. It can assess the size and the location of the tumour. It can also diagnose hepatic metastasis. [10]

Obscure gastrointestinal bleeding is very difficult to diagnose. Newer diagnostic techniques like video capsule endoscopy (VCE), contrast enhanced CT, CT angiography and 99m-Tc labelled Red Blood Cells (RBC) scan can localize the source of bleeding [11]. Orellana reported a high rate of correct localization of active GI bleeding up to $93 \%$ by RBC scans [12]. Positron emission tomography with $18-\mathrm{FDG}$ is particularly useful for detection of secondary localisation of GIST, but has been chiefly used for patient follow-up [13, 14].

The primary treatment of GIST is complete excision with surrounding tissue. The survival correlates directly with the completeness of the removal. Resectable GIST with low risk factors should be observed only and the high risk cases should be considered for imatinib. The unresectable GIST should be considered for imatinib or complementary resection. The GIST not responding to imatinib may be managed by dose escalation or trial of experimental agents [15].

Synchronous hepatic metastases must be resected if surgically feasible. The unresectable tumours may be treated with 
neoadjuvant Imatinib and subsequent complementary resection. Even if a tumour is unresectable, resection is palliative for mass effect and bleeding [16]. Lymph node dissection is usually not needed because like sarcomas, GIST metastasizes through blood and lymphatic spread is very late.

Imatinib is a tyrosine kinase inhibitor and offers very specific antitumour effect against GISTs. Its role in inoperable and metastatic disease has been proved $[17,18]$.

\section{CONCLUSION}

GISTs are rare but clinical important tumours. As in our case they can cause life threatening bleeding. Intensive care to stabilize the patient and modern diagnostic methods like RBC scan has proved invaluable. Complete resection of the tumour has been the definitive treatment of the tumour and the gastrointestinal haemorrhage.

\section{CONFLICT OF INTEREST}

Authors have no conflict of interest to declare

\section{REFERENCES}

1. Mazur MT, Clark HB. Gastric stromal tumors. Reappraisal ofhistogenesis. Am J Surg Pathol. 1983; 7(6): 507-519.

2. Kindblom LG, Remotti HE, Aldenborg F, Meis-Kindblom JM. Gastrointestinal pacemaker cell tumour (GIPACT): gastrointestinal-stromal-tumours show phenotypic characteristics of the interstitial cells of Cajal. Am J Pathol. 1998; 152(5): 1259-1269.

3. Miettinen M, Lasota J. Gastrointestinal stromal tumors definition, clinical, histological and molecular genetic features and differential diagnosis. Virchows Arch. 2001; 438(1): 1-12.

4. Miettinen M, Majidi M, Lasota J. Pathology and diagnostic criteria of gastrointestinal stromal tumours (GISTs): a review. Eur $J$ Cancer. 2002; 38(supl 5): S39-S51.

5. Miettinen M, Sarlomo-Rikala M, Lasota J. Gastrointestinal stromal tumours. Ann Chir Gynaecol. 1998; 87(4): 278-281.

6. Dematteo RP, Lewis JJ, Leung D, Mudan SS, Woodruff JM, Brennan MF. Two hundred gastrointestinal stromal tumours: recurrence patterns and prognostic factors for survival. Ann Surg. 2000; 231(1): 51-58.
7. Nilsson B, Bumming P, Meis-Kindblom JM, Oden A, Dortok A, Gustavsson B. Gastrointestinal stromal tumors: the incidence, prevalence, clinical course, and prognostication in the preimatinib mesylate era - a population-based study in western Sweden. Cancer. 2005; 103(4): 821-829.

8. Ludwig DJ, Traverso LW. Gut stromal tumours and their clinical behavior. Am J Surg. 1997; 173: 390-394.

9. Catena F, Pasqualini E, Campione O. Gastrointestinal Stromal Tumours: experience of an emergency surgery department. Dig Surg. 2000; 17: 503-507.

10. Bucher P, Villiger P, Egger JF, Buhler LH, Morel P. Management of gastrointestinal stromal tumours: from diagnosis to treatment. Swiss Med Wkly. 2004; 134(11-12): 145-153.

11. Hadithi M, Heine GD, Jacobs MA, Van Bodegraven AA, Mulder CJ. A prospective study comparing video capsule endoscopy with double balloon enteroscopy in patients with obscure gastrointestinal bleeding. Am J Gatroenterol. 2006; 101(1): 52-57.

12. Orellana P, Vial I, Prieto C. $99 \mathrm{mTc}$ red blood cell scintigraphy for the assessment of active gastrointestinal bleeding. Rev Med Chil. 1998; 126(4): 413-418.

13. Van den Abbeele A, Badawi R. Use of positron emission tomography in oncology and its potential role to assess response to imatinib mesylate therapy in gastrointestinal stromal tumours (GISTs). Eur J Cancer. 2002; 38(Supl 5): S60-S65.

14. Stroobants S, Goeminne J, Seegers M, Dimitrijevic S, Dupont P, Nuyts J. 18FDGPositron emission tomography for the early prediction of response in advanced soft tissue sarcoma treated with imatinib mesylate (Glivec). Eur J Cancer. 2003; 39(14): 2012-2020.

15. Dematteo RP, Lewis JJ, Leung D, Mudan SS, Woodruff JM, Brennan MF. Two hundred gastrointestinal stromal tumours: recurrence patterns and prognostic factors for survival. Ann Surg. 2000; 231(1): 51-58.

16. He LJ, Wang BS, Chen CC. Smooth muscle tumours of the digestive tract: report of 160 cases. Br J Surg. 1988; 75(2): 184-186.

17. Hassan I, You YN, Shyyan R, Dozois EJ, Smyrk TC, Okuno SH. Surgically managed gastrointestinal stromal tumors: a comparative and prognostic analysis. Ann Surg Oncol. 2008; 15(1): 52-59.

18. Blay JY, Bonvalot S, Casali P, Choi H, DebiecRichter M, Dei Tos AP. Consensus meeting for the management of gastrointestinal stromal tumors. Report of the GIST Consensus Conference of 20-21 March 2004, under the auspices of ESMO. Ann Oncol. 2005; 16(4): 566-578. 